\title{
Activity of Phytochemical Constituents of Black Pepper and Rosemary Against Zilka Virus: An In silico Approach
}

\author{
Deneshraj Srinivasan $^{1}$ (D), Manigandan Venkatesan ${ }^{1, *(D)}$ \\ 1 Department of Pharmaceutical Technology, University College of Engineering, Bharathidasan Institute of Technology, \\ Anna University, Tiruchirappalli, India; deneshrajtinu @ gmail.com (D.S.); manimadhan2001@gmail.com (M.V.); \\ * Correspondence: manimadhan2001@gmail.com (M.V.);
}

Received: 1.08.2021; Revised: 27.08.2021; Accepted: 30.08.2021; Published: 4.09.2021

\begin{abstract}
Zika Virus is an emerging viral disease, and its outbreak rapidly affects human health worldwide. Many research findings are going on to find effective antiviral therapeutics for treating the Zika virus since there is no immunization or medications available in practice. In this study, the inhibitory potential of selected 72 phytochemicals derived from Piper nigrum and Salvia rosmarinus were tested against RNA-dependent RNA polymerase of ZIKV. The structure of NS5 RdRp was predicted using the SWISS-MODEL, and the structural stability was evaluated using GROMACS. Drug-likeness properties were predicted using SwissADME, MolSoft, and PreADMET servers. The results exhibited that 57 phytochemicals, i.e., 26 from Piper nigrum and 31 from Salvia rosmarinus showed effective drug-likeness. These phytochemicals were docked against predicted binding sites of RdRp ZIKV using AutoDock Vina, and pharmacokinetic properties were also analyzed. This investigation has revealed that out of 57 phytochemicals, Piperine $(-7.6 \mathrm{Kcal} / \mathrm{mol})$ and Isoscutellarein ($7.4 \mathrm{Kcal} / \mathrm{mol}$ ) have shown significant inhibitory potential compared to those of these currently utilized antiviral drugs against ZIKV selected target. Thus our research findings strongly suggested that phytochemicals derived from Black pepper and rosemary could be beneficial against ZIKV.
\end{abstract}

Keywords: Zika Virus; phytochemicals; NS5; RdRp; molecular docking; molecular dynamic simulations.

(C) 2021 by the authors. This article is an open-access article distributed under the terms and conditions of the Creative Commons Attribution (CC BY) license (https://creativecommons.org/licenses/by/4.0/).

\section{Introduction}

ZIKA Virus (ZIKV) is one of the possible epidemic-causing viruses in tropical and subtropical regions. The first human case of ZIKV was in 1952 in Uganda and the United Republic of Tanzania [1, 2]. ZIKV is a member of the Flavivirus genus, which belongs to the Flaviviridae family. This genus comprises Dengue, West Nile, Yellow fever, Tick-borne encephalitis, Japanese encephalitis, Murray Valley encephalitis, and St. Louis encephalitis viruses [3]. ZIKV is a positive sense, single-stranded ribonucleic acid (RNA) virus with a genome size of approximately 10.8 kilobases. The ZIKV is made up of three structural proteins and seven non-structural proteins. The structural proteins include Capsid (C), membrane (M), and Envelope (E) proteins. NS1, NS2A, NS2B, NS3, NS4A, NS4B, and NS5 are the nonstructural protein present in ZIKV [4]. The NS5 protein contains methyltransferases (MTase) at the N-terminal and RNA-dependent RNA polymerase (RdRp) at the C-terminal. The RdRp facilitates the replication of the viral genome, which is essential for the virus's life cycle. It also acts as the most conservative protein of the flavivirus genus, thus making it one of the most promising targets for antiviral drugs [5-7]. 
The Discovery of drugs has become easy with the help of computational drug designing. The targets and medications are screened using various methods, which aid in determining the best drug for a given condition. Despite the several screening methods available, there is no authorized treatment or vaccine for ZIKV [8, 9]. The effects of ZIKV are evident due to the lack of effective treatment. One of the most agonizing effects is GuillainBarre syndrome, which affects the fetus (during gestation), causing paralysis as a long-term effect [10]. ZIKV's transmission mode is mosquito (Aedes and Culex genus), intrauterine and intrapartum transmission, sexual transmission, blood transmission, laboratory exposure, organ transplantation [11].

Piper nigrum and Salvia rosmarinus are the plants used in this in silico study to dock against the RdRp enzyme. Piper nigrum is commonly known as black pepper and is a member of the Piperaceae family. It is also known as black gold, a name with a fascinating history. Piper nigrum is used as a spice in many countries. The pharmacological activities are antioxidant, antimicrobial, antidiarrheal, antipyretic, analgesic, anti-inflammatory, anticonvulsant, antitussive, bronchodilator, antitumor, antidepressant, antiprotozoal, and insecticidal [12]. The pharmacological potential of black pepper is due to the presence of metabolites like phenolic compounds, alkaloids, flavonoids, carotenoids, terpenoids, etc., [13-16]. Salvia Rosmarinus, also known as rosemary, is a plant in the Lamiaceae family. Salvia rosmarinus has antibacterial, anti-inflammatory, antidiabetic, antitumor, antioxidant, and hepatoprotective properties. The presence of flavonoids, terpenoids, phenolic compounds, and other compounds contributes to these pharmacological activities [17-21]. This study is intended to examine the phytoconstituents available in both plant sources that could show better inhibiting potential against RdRp protein of ZIKV by using the In silico approach.

\section{Materials and Methods}

The methodology is divided into several techniques and phases. The flowchart provides an overview (Figure 1: The flowchart Figure 1). The final docking scores of these phytochemicals are compared to those of favipiravir and sofosbuvir [22], which are currently used for ZIKV treatment.

\subsection{Homology modeling.}

The RCSB Protein Data Bank was used to find the crystal structures of NS5 RNAdependent RNA polymerase [23]. ZIKV RdRp accession codes are 5WZ3 [24], 5U04 [25], 5U0C, and 5U0B [26]. Now the crystal structures are screened according to their resolution. Because of higher resolution $\left(3 \mathrm{~A}^{0}\right), 5 \mathrm{U} 0 \mathrm{C}$ and $5 \mathrm{U} 0 \mathrm{~B}$ were excluded from the studies. $5 \mathrm{WZ} 3$ and $5 \mathrm{U} 04$ have resolutions of $1.8 \mathrm{~A}^{0}$ and $1.9 \mathrm{~A}^{0}$, respectively, and they had missing amino acid residues. MEGA X: Molecular Evolutionary Genetics Analysis was used to align the sequences [27]. 5U04 was removed from the study due to a high number of missing residues. The SWISSMODEL was used to construct the missing residues of 5WZ3 [28-29]. Based on the QMEAN (Qualitative Model Energy ANalysis), 6LD1 (ZIKA/ French Polynesia NS5 polymerase domain) [30] was used as the template for modeling. The complete RdRp protein is now obtained from SWISS-MODEL. Further, we processed the ZIKV RdRp structure for energy minimization using UCSF Chimera [31]. The ZIKV RdRp modeled protein was selected as a final target for virtual screening. 


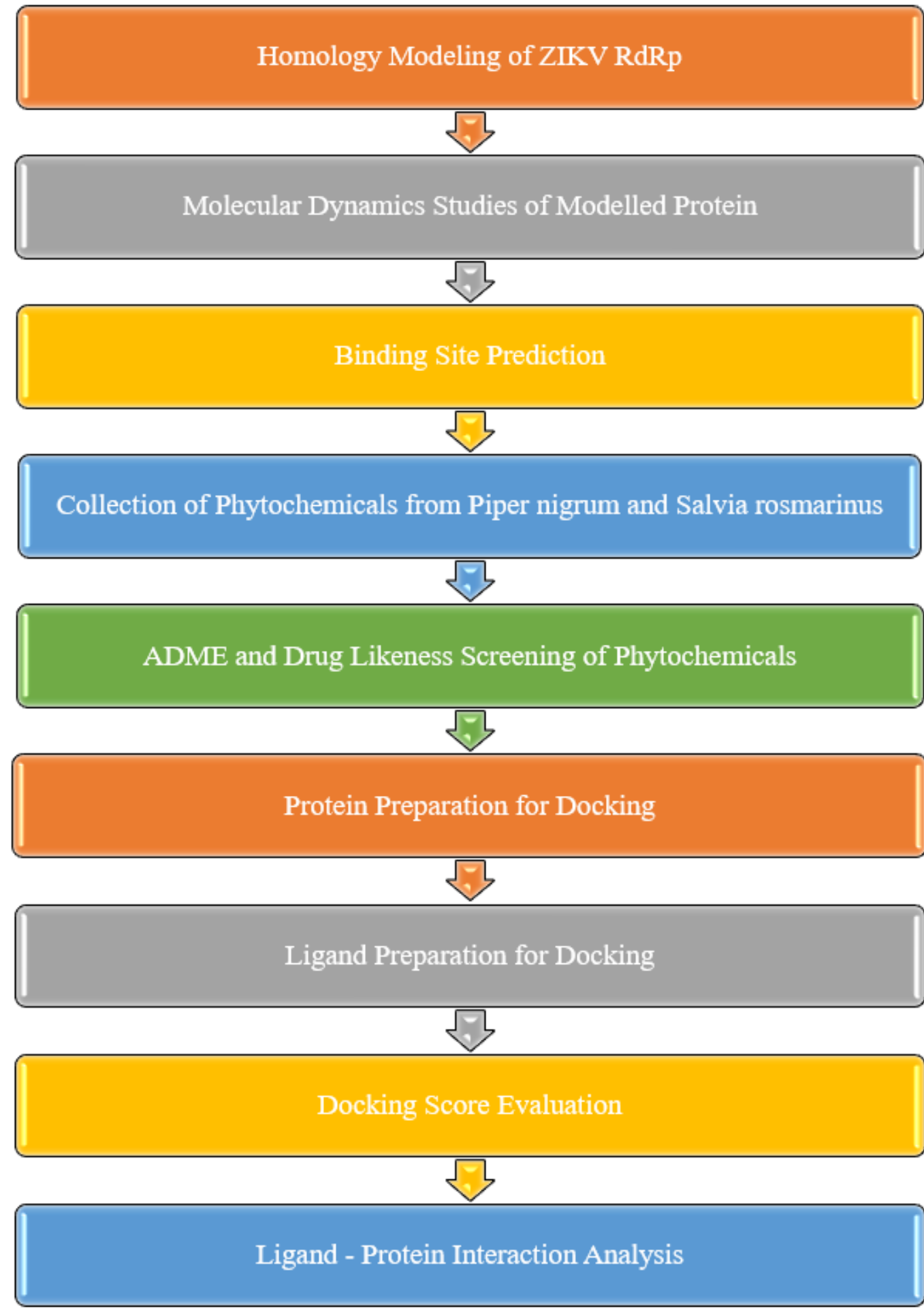

Figure 1. The flowchart representing the step-by-step methodology of the experiment conducted.

\subsection{Molecular dynamics.}

Molecular dynamics simulation was studied with the help of GROMACS (GROningen MAchine for Chemical Simulations) 2021.2 version [32-33]. Primarily, the atoms were applied with the AMBER99 force field [34-35]. The solvent is neutralized with $\mathrm{Na}^{+}$and $\mathrm{Cl}^{-}$in $0.15 \mathrm{M}$ concentration using Verlett cut-off scheme. The energy minimization was done with the steepest descent algorithm, having 50,000 steps. Equilibration of the whole system was done with NVT (Constant Number, Volume, and Temperature) and NPT (Constant Number, Pressure and Temperature). The temperature and pressure, i.e., $300 \mathrm{k}$ and $1 \mathrm{~atm}$, were constant 
for $100 \mathrm{ps}$. The molecular production dynamics were simulated for $1 \mathrm{~ns}$. The results were saved, and the RMSD plot was derived from the result. The simulation visualization was done in VMD, and further analysis was done [36-37].

\subsection{Binding region prediction.}

The binding region for the RdRp protein is analyzed from ProteinsPlus [38], deep site [39], and CASTp [40]. Almost all the three servers have shown similar binding sites. The binding sites were noted for docking purposes.

\subsection{Ligand preparation.}

Phytochemicals present in Piper nigrum and Salvia rosmarinus are known to have inhibitory action against viral diseases [41-42]. About 31 phytochemicals from Piper nigrum and 41 phytochemicals from Salvia rosmarinus were primarily selected to analyze their antiviral activity against ZIKV. The structures of these phytochemicals and antiviral agents (favipiravir and sofosbuvir) are retrieved from PubChem [43], IMPPAT (Indian Medicinal Plants, Phytochemistry And Therapeutics) [44]. Initially, the 3D-SDF format of these ligands was retrieved, then converted into PDB format using Open Babel [45-46].

\subsection{ADME prediction and drug-likeness.}

Pharmacokinetic properties and drug-likeness of the phytoconstituents from Piper nigrum and Salvia rosmarinus were analyzed using SwissADME server [47], Molsoft Online Server [48], and PreADMET server [49]. Based on Lipinski's rule of five [50], the phytochemicals were screened. A total of 26 phytochemicals from Piper nigrum and 31 phytochemicals from Salvia rosmarinus were confirmed for docking purposes.

\subsection{Molecular docking.}

The structures of the ZIKV RdRp protein and ligand were converted from PDB to PDBQT format using AutoDock MGLTools v.1.5.6 [51]. Torsion adjustments, the addition of Gasteiger charges, and other modifications were made to prepare ligands. The grid box was also created to cover the protein's binding region. The molecular docking was then performed with AutoDock Vina v.1.1.2 [52]. The docking results have been obtained. The ligands with a docking score less than $-7.4 \mathrm{Kcal} / \mathrm{mol}$ were further taken for interaction studies. The proteinligand interactions were analyzed using PyMOL [53] and Biovia Discovery Studio Visualizer [54].

\section{Results and Discussion}

\subsection{Structure of ZIKV RdRp binding sites.}

SWISS-MODEL presented 36 templates for the 5WZ3 ZIKV RdRp sequence, with the template 6LD1 (ZIKV/ French Polynesia NS5 Polymerase domain) having 0.99 percentage query coverage and 100 percentage sequence similarity. For template 6LD1, the GMQE (Global Model Quality Estimation) and QMEAN (Qualitative Model Energy ANalysis) scores were 0.85 and $0.79 \pm 0.05$, respectively. The ZIKV RdRp model protein (Figure 2) and its binding sites were analyzed (Figure 3). The Ramachandran plot for the ZIKV RdRp protein 
was generated in the SWISS-MODEL. As per the Ramachandran plot analysis of $\varphi$ and $\psi$ angles for individual amino acid residues in ZIKV RdRp, it was observed that $94.27 \%$ residues were present in the favored region and $4.75 \%$ residues in allowed regions while only $0.98 \%$ residues were in the outlier region (Figure 4). Apart from the Ramachandran outliers, the protein also has rotamer outliers of about $0.75 \%$. The total number of bad angles present in the chain is 25 . The torsional angles of this protein are good, according to the Ramachandran plot study. As a result, the structure is more reliable.

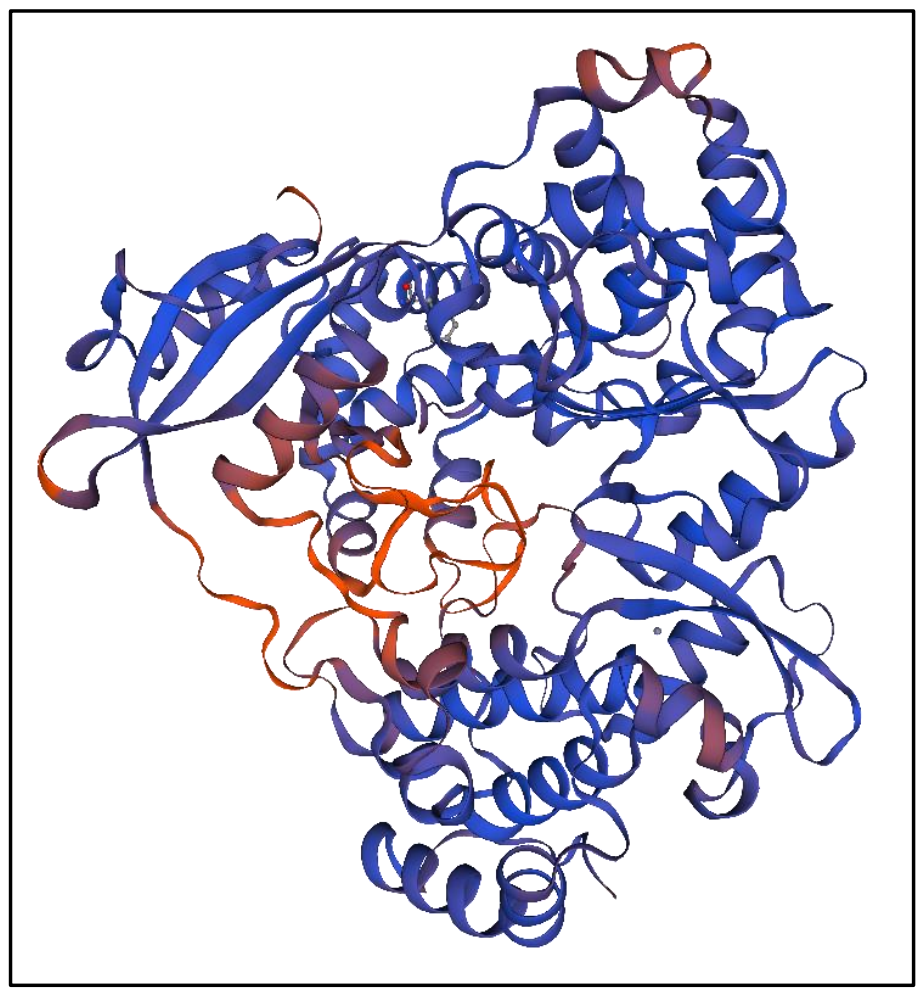

Figure 2. ZIKV RdRp modeled protein structure with template 6LD1. The red regions showing the filling of missed residues in the protein sequence.

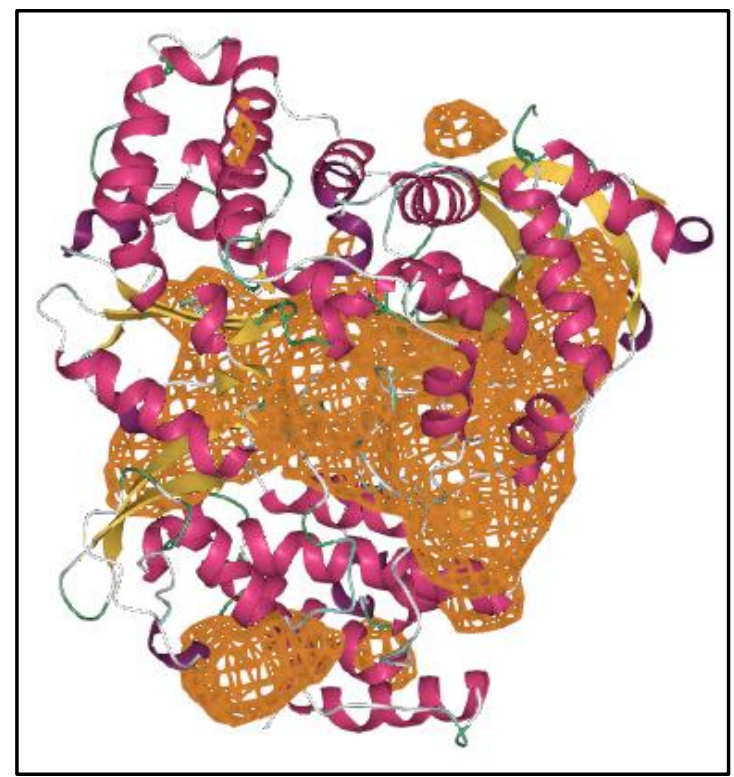

Figure 3. The binding regions of the ZIKV RdRp are highlighted in the figure.

\subsection{Molecular dynamics and simulation.}


The potential energy of the protein model was $-1929900 \mathrm{~J}$ after it was subjected to energy minimization. The equilibration was then completed at standard temperature and pressure. Temperature, pressure, and density changes were observed as time progressed. Protein instability was observed as temperature (mesophilic) and pressure increased (piezotolerant). Then the rmsd (Root Mean Square Deviation) value for the protein backbone for the simulation period $1 \mathrm{~ns}$ was calculated (Figure 5). The average rmsd value was found to be $0.25 \mathrm{~A}^{0}$. This study has shown that the predicted protein is stable in the ion-solvent environment simulation.

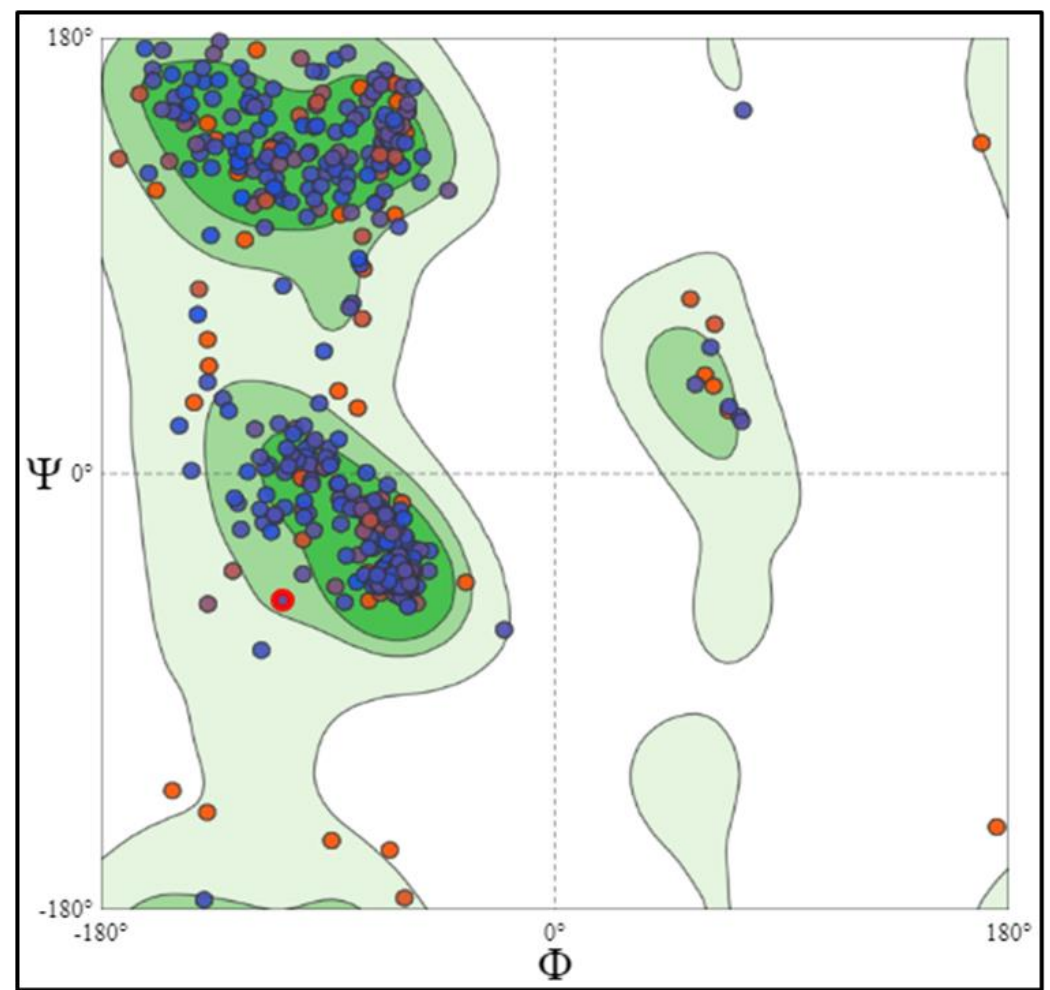

Figure 4. Ramachandran plot for ZIKV RdRp from SWISS-MODEL, showing the angles present in favored, allowed, and unfavoured regions.



Figure 5. RMSD plot for protein backbone.

\subsection{Drug suitability and their virtual screening.}


Drug-likeness predictions were performed for 72 phytochemicals from Piper nigrum and Salvia rosmarinus. Only 57 phytochemicals passed through drug-likeness screening, with 26 from Piper nigrum and 31 from Salvia rosmarinus. The Lipinski rule of five data for phytoconstituents is present in Table 1 and Table 2.

Table 1. Lipinski rule of five properties and binding energy of Piper nigrum phytochemicals.

\begin{tabular}{l|l|l|l|l|l} 
Compounds & $\begin{array}{l}\text { Binding } \\
\text { Energy } \\
\text { kcal/mol }\end{array}$ & $\begin{array}{l}\text { Molecular } \\
\text { Weight } \\
\text { (g/mol) }\end{array}$ & $\begin{array}{l}\text { Hydrogen } \\
\text { Bond Acceptor }\end{array}$ & $\begin{array}{l}\text { Hydrogen } \\
\text { bond } \\
\text { Donor }\end{array}$ & MLogP \\
\hline BRACHYAMIDE B & -5.4 & 327.42 & 3 & 0 & 3.08 \\
\hline CARYOPHYLLENEOXIDE & -6.4 & 220.35 & 1 & 0 & 3.67 \\
\hline CINNAMIC ACID & -4.5 & 148.16 & 2 & 1 & 1.90 \\
\hline DIHYDROPIPERICIDE & -5.9 & 343.46 & 3 & 1 & 3.31 \\
\hline EUGENOL & -4.2 & 164.20 & 2 & 1 & 2.01 \\
\hline LIMONENE & -5.6 & 136.23 & 0 & 0 & 3.27 \\
\hline METHYLEUGENOL & -4.7 & 178.23 & 2 & 0 & 2.30 \\
\hline MYRCENE & -4.2 & 136.23 & 0 & 0 & 3.56 \\
\hline MYRISTICIN & -4.9 & 192.21 & 3 & 0 & 1.70 \\
\hline PIPERAMIDE & -4.5 & 304.43 & 3 & 1 & 1.32 \\
\hline PIPERANINE & -5.5 & 280.41 & 1 & 0 & 3.51 \\
\hline PIPERETTINE & -6.0 & 287.35 & 3 & 0 & 2.47 \\
\hline PIPERICIDE & -6.3 & 311.37 & 3 & 0 & 0.43 \\
\hline PIPERINE & -4.5 & 341.44 & 3 & 1 & 3.23 \\
\hline PIPEROLEIN B & -7.6 & 285.34 & 3 & 0 & 2.39 \\
\hline PIPERONAL & -4.6 & 343.46 & 3 & 0 & 3.39 \\
\hline PIPERONIC ACID & -5.1 & 150.13 & 3 & 0 & 0.52 \\
\hline PIPERYLINE & -6.0 & 218.21 & 4 & 1 & 1.51 \\
\hline RETROFRACTAMIDE A & -6.2 & 271.31 & 3 & 0 & 2.14 \\
\hline SAFROLE & -5.1 & 327.42 & 3 & 1 & 3.00 \\
\hline SARMENTINE & -5.6 & 162.19 & 2 & 0 & 2.02 \\
\hline SARMENTOSINE & -4.4 & 221.34 & 1 & 0 & 2.69 \\
\hline TERPINOLENE & -5.6 & 275.26 & 8 & 0 & -2.99 \\
\hline TRANSANETHOLE & -5.7 & 136.23 & 0 & 0 & 3.27 \\
\hline TRICHOLEINE & -4.4 & 148.20 & 1 & & 2.67 \\
\hline & -6.9 & 329.43 & 3 & 3.17
\end{tabular}

Table 2. Lipinski rule of five and binding energy for Salvia rosmarinus phytochemicals.

\begin{tabular}{l|l|l|l|l|l} 
Compounds & $\begin{array}{l}\text { Binding Energy } \\
\text { kcal/mol }\end{array}$ & $\begin{array}{l}\text { Molecular } \\
\text { Weight } \\
\text { (g/mol) }\end{array}$ & $\begin{array}{l}\text { Hydrogen } \\
\text { Acceptor }\end{array}$ & $\begin{array}{l}\text { Hydrogen } \\
\text { Bond } \\
\text { Donor }\end{array}$ & MLogP \\
\hline (E)-BETA-OCIMENE & -4.4 & 136.13 & 0 & 0 & -0.72 \\
\hline 1,8 CINEOLE & -5.5 & 154.14 & 1 & 0 & -1.69 \\
\hline ALPHA-PINENE & -6.7 & 136.13 & 0 & 0 & 4.14 \\
\hline APIGENIN & -7.3 & 270.05 & 5 & 3 & 1.59 \\
\hline BETA PINENE & -7.3 & 136.13 & 0 & 0 & 4.14 \\
\hline BETULINIC ACID & -6.8 & 456.36 & 3 & 2 & -4.32 \\
\hline BORNEOL & -5.6 & 154.14 & 1 & 1 & -1.16 \\
\hline CAFFEIC ACID & -5.5 & 180.04 & 4 & 3 & -0.91 \\
\hline CAMPHENE & -5.5 & 136.13 & 0 & 0 & -0.15 \\
\hline CAMPHOR & -5.5 & 152.12 & 1 & 0 & -1.24 \\
\hline CARNOSIC ACID & -6.8 & 332.2 & 4 & 3 & -1.92 \\
\hline CARNOSOL & -7.0 & 330.18 & 4 & 2 & -0.97 \\
\hline CARVACROL & -5.3 & 150.1 & 1 & 2 & -0.43 \\
\hline CIRSIMARITIN & -6.8 & 314.08 & 6 & 1 & 0.57 \\
\hline ROSMADIAL & -6.6 & 344.16 & 6 & 3 & -1.34 \\
\hline EPIROSMANOL & -7.3 & 346.18 & 5 & 2 & -1.88 \\
\hline GENKWANIN & -6.6 & 284.07 & 5 & 3 & 1.36 \\
\hline HESPERETIN & -7.1 & 302.08 & 6 & 4 & -0.66 \\
\hline ISOSCUTELLAREIN & -7.4 & 286.05 & 6 & 4 & 0.85 \\
\hline LUTEOLIN & -7.2 & 286.05 & 6 & 2 & 0.84 \\
\hline MICROMERIC ACID & -7.0 & 454.34 & 3 & -4.21 \\
\hline KAEMPFEROL & -7.1 & 286.05 & 6 & 2 & -0.24 \\
\hline OLEANOLIC ACID & -7.1 & 456.36 & 3 & -4.99 \\
\hline PECTOLINARIGENIN & -7.1 & 314.08 & 6 & 0.26 \\
\hline ROSMANOL & -7.0 & 346.18 & 5 & -1.88 \\
\hline
\end{tabular}




\begin{tabular}{l|l|l|l|l|l}
\hline Compounds & $\begin{array}{l}\text { Binding Energy } \\
\text { kcal/mol }\end{array}$ & $\begin{array}{l}\text { Molecular } \\
\text { Weight } \\
\text { (g/mol) }\end{array}$ & $\begin{array}{l}\text { Hydrogen Bond } \\
\text { Acceptor }\end{array}$ & $\begin{array}{l}\text { Hydrogen } \\
\text { Bond } \\
\text { Donor }\end{array}$ & MLogP \\
\hline ROSMARIDIPHENOL & -7.2 & 316.2 & 3 & 2 & -1 \\
\hline ROSMARINIC ACID & -6.9 & 360.08 & 8 & 5 & -1.9 \\
\hline ROSMARIQUINONE & -7.1 & 282.16 & 2 & 0 & -0.7 \\
\hline SALVIGENIN & -6.5 & 328.09 & 6 & 1 & 0.47 \\
\hline SCUTELLAREIN & -7.3 & 286.05 & 6 & 4 & 0.77 \\
\hline URSOLIC ACID & -7.3 & 456.36 & 3 & 2 & -4.94
\end{tabular}

3.4. Docking studies and analysis.

ZIKV RdRp protein was docked with 57 phytochemicals that passed the Lipinski rule of five. Piperine and isoscutellarein were chosen for comparison with antiviral drugs due to their high binding energy. The ligand interactions were also analyzed. Based on binding energy, the two phytochemicals perform better than Sofosbuvir and Favipiravir. The binding energy results of phytochemicals are given in Table 3. The binding energy results of antiviral drugs are given in Table 4. The ligand interaction shows multiple hydrogen bonds. The proteinligand interaction of Piperine and Isoscutellarein are shown in Figure 6 and Figure 7.

Table 3. Binding energy interactions of phytochemicals.

\begin{tabular}{l|l|l|l|l|l} 
Compounds & $\begin{array}{l}\text { Binding affinity } \\
\text { (Kcal/mol) }\end{array}$ & $\begin{array}{l}\text { No of hydrogen } \\
\text { bonds }\end{array}$ & $\begin{array}{l}\text { H-bond } \\
\text { interactions }\end{array}$ & Bond distance & $\begin{array}{l}\text { Non-covalent bond } \\
\text { interactions }\end{array}$ \\
\hline PIPERINE & -7.6 & 3 & LYS193 & 2.49336 & TRP529 \\
& & & LYS194 & 2.96395 & ARG471 \\
& & SER444 & 2.7271 & LYS193 \\
\hline ISOSCUTELLAREIN & -7.4 & 4 & ASN448 & 2.56054 & TRP580 \\
& & & ARG576 & 2.10883 & \\
& & GLU439 & 2.77899 & \\
& & HIS446 & 3.29233 &
\end{tabular}

Table 4. Binding energy interactions of antiviral drugs.

\begin{tabular}{l|l|l|l|l|l} 
Compounds & $\begin{array}{l}\text { Binding affinity } \\
\text { (Kcal/mol) }\end{array}$ & $\begin{array}{l}\text { No of hydrogen } \\
\text { bonds }\end{array}$ & $\begin{array}{l}\text { H-bond } \\
\text { interactions }\end{array}$ & Bond distance & $\begin{array}{l}\text { Non-covalent } \\
\text { interactions }\end{array}$ \\
\hline SOFOSBUVIR & -6.9 & 4 & ASN186 & 2.15536 & TRP211 \\
& & & LEU212 & 2.15399 & PHE164 \\
& & & LYS312 & 2.89084 & ALA158 \\
& & & TYR209 & 2.31429 & \\
\hline FAVIPIRAVIR & -6.0 & 5 & ARG526 & 2.80069 & SER138 \\
& & & SER138 & 2.44811 & GLU151 \\
& & & GLU148 & 2.7207 & VAL136 \\
& & VAL136 & 3.50141 & ALA155
\end{tabular}

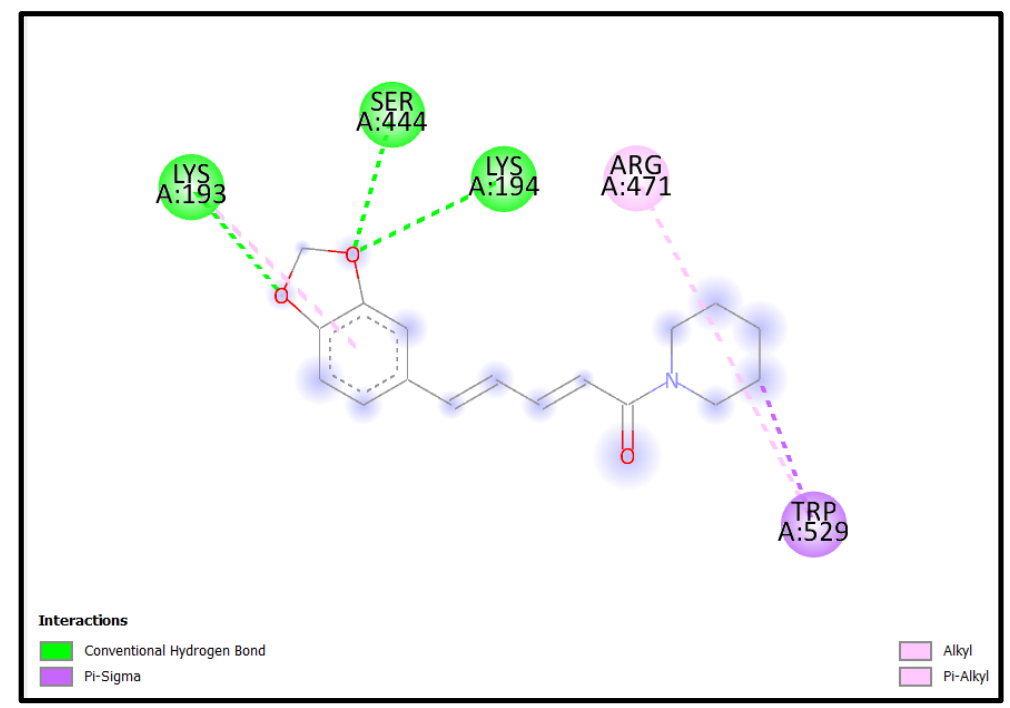

Figure 6. Binding site interactions of Piperine showing six bonds, including three hydrogen bonds. 


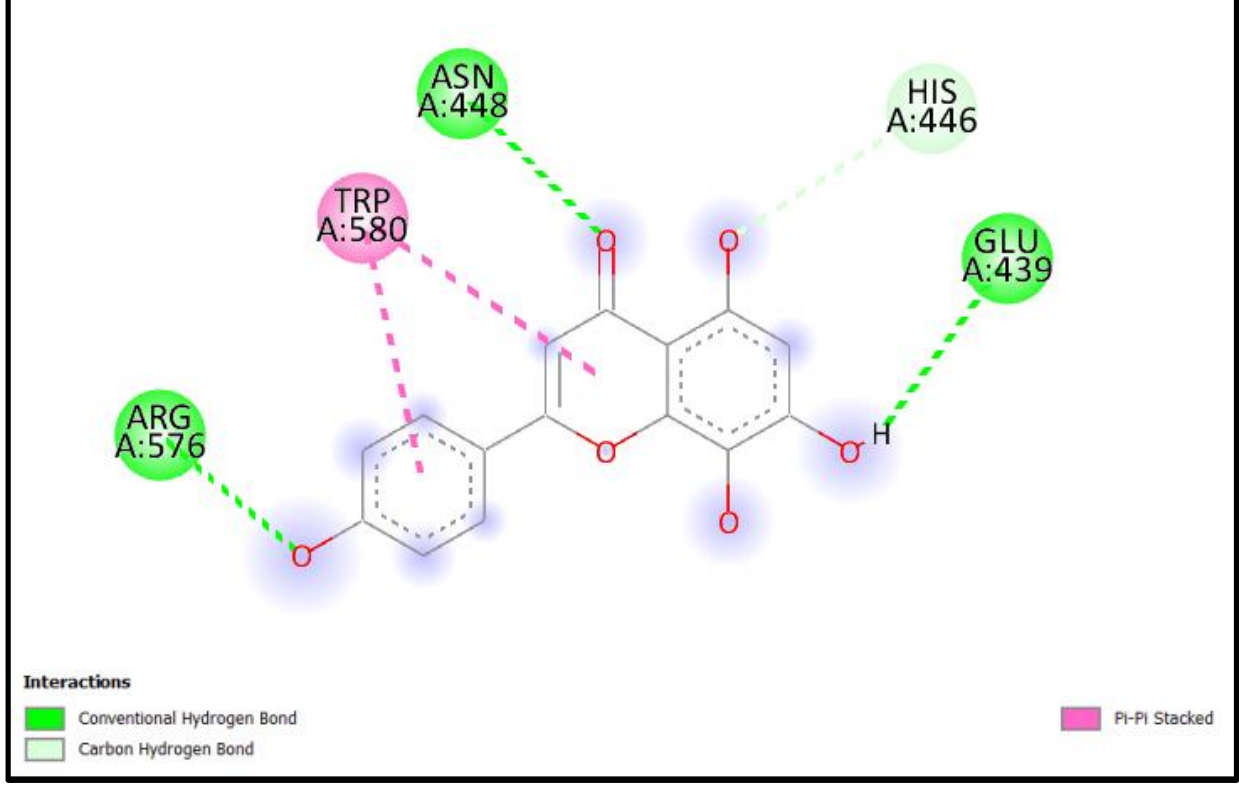

Figure 7. Binding site interactions of Isoscutellarein showing five bonds, including four hydrogen bonds.

\subsection{Pharmacokinetic property analysis.}

Piperine and isoscutellarein were subjected to ADME analysis after showing better binding affinity with the RdRp protein of ZIKV. The data revealed that the phytochemicals possessed good pharmacokinetic properties of druggability with a higher bioavailability score than antiviral drugs currently used for ZIKV treatment. The results are represented in Table 5 and Table 6.

Table 5. Pharmacokinetic Properties of phytochemicals.

\begin{tabular}{l|c|c|c|c|c} 
Phytochemicals & ESOL LogS & ESOL Class & GI absorption & BBB permeant & $\begin{array}{c}\text { Bioavailability } \\
\text { score }\end{array}$ \\
\hline Piperine & -3.74 & Soluble & High & No & 0.55 \\
\hline Isoscutellarein & -3.79 & Soluble & High & No & 0.55
\end{tabular}

Table 6. Pharmacokinetic Properties of antiviral drugs.

\begin{tabular}{l|c|c|c|c|c} 
Phytochemicals & ESOL LogS & ESOL Class & GI absorption & BBB permeant & $\begin{array}{c}\text { Bioavailability } \\
\text { score }\end{array}$ \\
\hline Sofosbuvir & -3.27 & Soluble & Low & No & 0.17 \\
\hline Favipiravir & -0.80 & Very soluble & High & No & 0.55
\end{tabular}

\section{Conclusions}

Our current investigation attempted to investigate the capability of natural sources from Piper nigrum (Black pepper) and Salvia rosmarinus (Rosemary) against the RdRp protein of ZIKV in contrast with the proposed drugs, namely, Sofosbuvir and Favipiravir. Based on virtual screening and molecular docking analysis, the compounds, namely Piperine and Isoscutellarein, were identified as possible lead molecules to fight against ZIKV. The present In silico study proved that these phytochemicals could be effective for treating ZIKV and urge to analyze its potential in a pre-clinical and clinical test.

\section{Funding}

This research received no specific grant from any funding agency in the public, commercial, or not-for-profit sectors. 


\section{Acknowledgments}

This research has no acknowledgment.

\section{Conflicts of Interest}

The authors declare no conflict of interest.

\section{References}

1. Gubler, D.J.; Vasilakis, N.; Musso, D. History and Emergence of Zika Virus. The Journal of Infectious Diseases 2017, 216, S860-S867, https://doi.org/10.1093/infdis/jix451.

2. Musso, D.; Ko, A.I.; Baud, D. Zika Virus Infection - After the Pandemic. New England Journal of Medicine 2019, 381, 1444-1457, https://doi.org/10.1056/NEJMra1808246.

3. Noorbakhsh, F.; Abdolmohammadi, K.; Fatahi, Y.; Dalili, H.; Rasoolinejad, M.; Rezaei, F.; Salehi-Vaziri, M.; Shafiei-Jandaghi, N.Z.; Gooshki, E.S.; Zaim, M.; Nicknam, M.H. Zika Virus Infection, Basic and Clinical Aspects: A Review Article. Iran J Public Health 2019, 48, 20-31.

4. Sirohi, D.; Kuhn, R.J. Zika Virus Structure, Maturation, and Receptors. The Journal of Infectious Diseases 2017, 216, S935-S944, https://doi.org/10.1093/infdis/jix515.

5. Šebera, J.; Dubankova, A.; Sychrovský, V.; Ruzek, D.; Boura, E.; Nencka, R. The structural model of Zika virus RNA-dependent RNA polymerase in complex with RNA for rational design of novel nucleotide inhibitors. Scientific Reports 2018, 8, https://doi.org/10.1038/s41598-018-29459-7.

6. Yuan, J.; Yu, J.; Huang, Y.; He, Z.; Luo, J.; Wu, Y.; Zheng, Y.; Wu, J.; Zhu, X.; Wang, H.; Li, M. Antibiotic fidaxomicin is an RdRp inhibitor as a potential new therapeutic agent against Zika virus. BMC Medicine 2020, 18, https://doi.org/10.1186/s12916-020-01663-1.

7. Noreen; Ali, R.; Badshah, S.L.; Faheem, M.; Abbasi, S.W.; Ullah, R.; Bari, A.; Jamal, S.B.; Mahmood, H.M.; Haider, A.; Haider, S. Identification of potential inhibitors of Zika virus NS5 RNA-dependent RNA polymerase through virtual screening and molecular dynamic simulations. Saudi Pharmaceutical Journal 2020, 28, 1580-1591, https://doi.org/10.1016/j.jsps.2020.10.005.

8. Da Silva, S.; Oliveira Silva Martins, D.; Jardim, A.C. A Review of the Ongoing Research on Zika Virus Treatment. Viruses 2018, 10, https://doi.org/10.3390/v10050255.

9. Bernatchez, J.A.; Tran, L.T.; Li, J.; Luan, Y.; Siqueira-Neto, J.L.; Li, R. Drugs for the Treatment of Zika Virus Infection. Journal of Medicinal Chemistry 2020, 63, 470-489, https://doi.org/10.1021/acs.jmedchem.9b00775.

10. Uncini, A.; Shahrizaila, N.; Kuwabara, S. Zika virus infection and Guillain-Barré syndrome: a review focused on clinical and electrophysiological subtypes. Journal of Neurology, Neurosurgery \&amp; amp; Psychiatry 2017, 88, https://doi.org/10.1136/jnnp-2016-314310.

11. Gregory, C.J.; Oduyebo, T.; Brault, A.C.; Brooks, J.T.; Chung, K.-W.; Hills, S.; Kuehnert, M.J.; Mead, P.; Meaney-Delman, D.; Rabe, I.; Staples, E.; Petersen, L.R. Modes of Transmission of Zika Virus. The Journal of Infectious Diseases 2017, 216, S875-S883, https://doi.org/10.1093/infdis/jix396.

12. Joshi, D.; Shrestha, A.; Adhikari, N. A Review On Diversified Use Of The King Of Spices: Piper Nigrum (Black Pepper). International Journal of Pharmaceutical Sciences and Research 2018, 9, 4089-4101.

13. Ashokkumar, K.; Murugan, M.; Dhanya, M.K.; Pandian, A.; Warkentin, T.D. Phytochemistry and therapeutic potential of black pepper [Piper nigrum (L.)] essential oil and piperine: a review. Clinical Phytoscience 2021, 7, https://doi.org/10.1186/s40816-021-00292-2.

14. Damanhouri, Z.A.; Ahmad, A. A review on therapeutic potential of Piper nigrum L. Black Pepper): The King of Spices. Med. Aromat. Plants 2014, 3, https://doi.org/10.4172/2167-0412.1000161.

15. Parmar, V.S.; Jain, S.C.; Bisht, K.S.; Jain, R.; Taneja, P.; Jha, A.; Tyagi, O.D.; Prasad, A.K.; Wengel, J.; Olsen, C.E.; Boll, P.M. Phytochemistry of the genus Piper. Phytochemistry 1997, 46, 597-673, https://doi.org/10.1016/S0031-9422(97)00328-2.

16. Nag, A.; Chowdhury, R.R. Piperine, an alkaloid of black pepper seeds can effectively inhibit the antiviral enzymes of Dengue and Ebola viruses, an in silico molecular docking study. VirusDisease 2020, 31, 308315, https://doi.org/10.1007/s13337-020-00619-6.

17. Ma, L.; Yao, L. Antiviral Effects of Plant-Derived Essential Oils and Their Components: An Updated Review. Molecules 2020, 25, https://doi.org/10.3390/molecules25112627.

18. Nieto, G.; Ros, G.; Castillo, J. Antioxidant and Antimicrobial Properties of Rosemary (Rosmarinus officinalis, L.): A Review. Medicines 2018, 5, https://doi.org/10.3390/medicines5030098.

19. Habtemariam, S. (2016). The Therapeutic Potential of Rosemary (Rosmarinus officinalis) Diterpenes for Alzheimer's Disease. Evidence-Based Complementary and Alternative Medicine 2016, 2016, https://doi.org/10.1155/2016/2680409. 
20. Andrade, J.M.; Faustino, C.; Garcia, C.; Ladeiras, D.; Reis, C.P.; Rijo, P. Rosmarinus officinalis L.: an update review of its phytochemistry and biological activity. Future Science OA 2018, 4, FSO283-FSO283, https://doi.org/10.4155/fsoa-2017-0124.

21. Ho, C.-T.; Wang, M.; Wei, G.-J.; Huang, T.-C.; Huang, M.-T. Chemistry and antioxidative factors in rosemary and sage. BioFactors 2000, 13, 161-166, https://doi.org/10.1002/biof.5520130126.

22. Usman, S.; Naz, Z.; Saleem, K.; Bashir, H.; Bilal, M.; Sumrin, A. The countermeasure for Zika virus: a hard nut to be cracked. Future Virology 2018, 13, 361-369, https://doi.org/10.2217/fvl-2018-0018.

23. Burley, S.K.; Berman, H.M.; Kleywegt, G.J.; Markley, J.L.; Nakamura, H.; Velankar, S. Protein Data Bank (PDB): The Single Global Macromolecular Structure Archive. In: Protein Crystallography: Methods and Protocols. Wlodawer, A.; Dauter, Z.; Jaskolski, M. Eds.; Springer New York: New York, NY, 2017; pp. 627641, https://doi.org/10.1007/978-1-4939-7000-1_26.

24. Duan, W.; Song, H.; Wang, H.; Chai, Y.; Su, C.; Qi, J.; Shi, Y.; Gao, G.F. The crystal structure of Zika virus NS5 reveals conserved drug targets. The EMBO Journal 2017, 36, 919-933, https://doi.org/10.15252/embj.201696241.

25. Godoy, A.S.; Lima, G.M.A.; Oliveira, K.I.Z.; Torres, N.U.; Maluf, F.V.; Guido, R.V.C.; Oliva, G. Crystal structure of Zika virus NS5 RNA-dependent RNA polymerase. Nature Communications 2017, 8, https://doi.org/10.1038/ncomms14764.

26. Zhao, B.; Yi, G.; Du, F.; Chuang, Y.-C.; Vaughan, R.C.; Sankaran, B.; Kao, C.C.; Li, P. Structure and function of the Zika virus full-length NS5 protein. Nature Communications 2017, 8, https://doi.org/10.1038/ncomms14762.

27. Kumar, S.; Stecher, G.; Li, M.; Knyaz, C.; Tamura, K. MEGA X: Molecular Evolutionary Genetics Analysis across Computing Platforms. Molecular Biology and Evolution 2018, 35, 1547-1549, https://doi.org/10.1093/molbev/msy096.

28. Waterhouse, A.; Bertoni, M.; Bienert, S.; Studer, G.; Tauriello, G.; Gumienny, R.; Heer, F.T.; de Beer, T.A P.; Rempfer, C.; Bordoli, L.; Lepore, R.; Schwede, T. SWISS-MODEL: homology modelling of protein structures and complexes. Nucleic acids research 2018, 46, W296-W303, https://doi.org/10.1093/nar/gky427.

29. Guex, N.; Peitsch, M.C.; Schwede, T. Automated comparative protein structure modeling with SWISSMODEL and Swiss-PdbViewer: A historical perspective. Electrophoresis 2009, 30, S162-S173, https://doi.org/10.1002/elps.200900140.

30. Gharbi-Ayachi, A.; Santhanakrishnan, S.; Wong Yee, H.; Chan Kitti, W.K.; Tan Siok, T.; Bates Roderick, W.; Vasudevan Subhash, G.; El Sahili, A.; Lescar, J.; Heise Mark, T. Non-nucleoside Inhibitors of Zika Virus RNA-Dependent RNA Polymerase. Journal of Virology 2020, 94, e00794-00720, https://doi.org/10.1128/JVI.00794-20.

31. Pettersen, E.F.; Goddard, T.D.; Huang, C.C.; Couch, G.S.; Greenblatt, D.M.; Meng, E.C.; Ferrin, T.E. UCSF Chimera-A visualization system for exploratory research and analysis. Journal of Computational Chemistry 2004, 25, 1605-1612, https://doi.org/10.1002/jcc.20084.

32. Lindahl, A.; Hess, S. GROMACS 2021.2 Manual (2021.2). Zenodo 2021, https://doi.org/10.5281/zenodo.4723561.

33. Pandit, S.A.; Bostick, D.; Berkowitz, M.L. Molecular Dynamics Simulation of a Dipalmitoylphosphatidylcholine Bilayer with NaCl. Biophysical Journal 2003, 84, 3743-3750, https://doi.org/10.1016/S0006-3495(03)75102-9.

34. DePaul, A.J.; Thompson, E.J.; Patel, S.S.; Haldeman, K.; Sorin, E.J. Equilibrium conformational dynamics in an RNA tetraloop from massively parallel molecular dynamics. Nucleic acids research 2010, 38, 48564867.

35. Guy, Andrew T.; Piggot, Thomas J.; Khalid, S. Single-Stranded DNA within Nanopores: Conformational Dynamics and Implications for Sequencing; a Molecular Dynamics Simulation Study. Biophysical Journal 2012, 103, 1028-1036, https://doi.org/10.1016/j.bpj.2012.08.012.

36. Humphrey, W.; Dalke, A.; Schulten, K. VMD: Visual molecular dynamics. Journal of Molecular Graphics 1996, 14, 33-38, https://doi.org/10.1016/0263-7855(96)00018-5.

37. Schulten, K.; Humphrey, W.; Logunov, I.; Sheves, M.; Xu, D. Molecular Dynamics Studies of Bacteriorhodopsin's Photocycles. Israel Journal of Chemistry 1995, 35, 447-464, https://doi.org/10.1002/ijch.199500042.

38. Schöning-Stierand, K.; Diedrich, K.; Fährrolfes, R.; Flachsenberg, F.; Meyder, A.; Nittinger, E.; Steinegger, R.; Rarey, M. ProteinsPlus: interactive analysis of protein-ligand binding interfaces. Nucleic acids research 2020, 48, W48-W53, https://doi.org/10.1093/nar/gkaa235.

39. Jiménez, J.; Doerr, S.; Martínez-Rosell, G.; Rose, A.S.; De Fabritiis, G. DeepSite: protein-binding site predictor using 3D-convolutional neural networks. Bioinformatics 2017, 33, 3036-3042, https://doi.org/10.1093/bioinformatics/btx350.

40. Tian, W.; Chen, C.; Lei, X.; Zhao, J.; Liang, J. CASTp 3.0: computed atlas of surface topography of proteins. Nucleic acids research 2018, 46, W363-W367, https://doi.org/10.1093/nar/gky473.

41. Srivastava, A.K.; Chaurasia, J.P.; Khan, R.; Dhand, C.; Verma, S. Role of medicinal plants of traditional use in recuperating devastating COVID-19 situation. Med Aromat Plants (Los Angeles) 2020, 9, 2167-0412. 
42. Al-Megrin, W.A.; AlSadhan, N.A.; Metwally, D.M.; Al-Talhi, R.A.; El-Khadragy, M.F.; Abdel-Hafez, L.J.M. Potential antiviral agents of Rosmarinus officinalis extract against herpes viruses 1 and 2. Bioscience Reports 2020, 40, https://doi.org/10.1042/BSR20200992.

43. Kim, S.; Chen, J.; Cheng, T.; Gindulyte, A.; He, J.; He, S.; Li, Q.; Shoemaker, B.A.; Thiessen, P.A.; Yu, B.; Zaslavsky, L.; Zhang, J.; Bolton, E.E. PubChem in 2021: new data content and improved web interfaces. Nucleic acids research 2021, 49, D1388-D1395, https://doi.org/10.1093/nar/gkaa971.

44. Mohanraj, K.; Karthikeyan, B.S.; Vivek-Ananth, R.P.; Chand, R.B.; Aparna, S.R.; Mangalapandi, P.; Samal, A. IMPPAT: a curated database of Indian medicinal plants, phytochemistry and therapeutics. Sci Rep 2018, 8.

45. O'Boyle, N.M.; Banck, M.; James, C.A.; Morley, C.; Vandermeersch, T.; Hutchison, G.R. Open Babel: An open chemical toolbox. Journal of Cheminformatics 2011, 3, https://doi.org/10.1186/1758-2946-3-33.

46. The Open Babel Package, 2005. Open Babel (version 2.3.1). Windows. Openbabel.org/Wiki/

47. Daina, A.; Michielin, O.; Zoete, V. SwissADME: a free web tool to evaluate pharmacokinetics, drug-likeness and medicinal chemistry friendliness of small molecules. Scientific Reports 2017, 7 , https://doi.org/10.1038/srep42717.

48. Molsoft drug-likeness and molecular property prediction Home Page. Available online: https://molsoft.com/mprop/ (accessed on 15 July 2021)

49. PreADMET Home Page. Available online: https://preadmet.bmdrc.kr/ (accessed on 17 July 2021)

50. Benet, L.Z.; Hosey, C.M.; Ursu, O.; Oprea, T.I. BDDCS, the Rule of 5 and drugability. Advanced Drug Delivery Reviews 2016, 101, 89-98, https://doi.org/10.1016/j.addr.2016.05.007.

51. Holt, P.A.; Chaires, J.B.; Trent, J.O. Molecular Docking of Intercalators and Groove-Binders to Nucleic Acids Using Autodock and Surflex. Journal of Chemical Information and Modeling 2008, 48, 1602-1615, https://doi.org/10.1021/ci800063v.

52. Trott, O.; Olson, A.J. AutoDock Vina: Improving the speed and accuracy of docking with a new scoring function, efficient optimization, and multithreading. Journal of Computational Chemistry 2010, 31, 455-461, https://doi.org/10.1002/jcc.21334.

53. The PyMOL Molecular Graphics System, Version 1.2r3pre, Schrödinger, LLC.

54. BIOVIA, Dassault Systèmes, Discovery studio Visualizer, v.2021, San Diego: Dassault Systèmes, 2021. 